\title{
Erratum to: Positive stone culture is associated with a higher rate of sepsis after endourological procedures
}

Jairam R. Eswara • Ahmad Shariftabrizi •

Dianne Sacco

Published online: 2 August 2013

(c) Springer-Verlag Berlin Heidelberg 2013

Erratum to: Urolithiasis

DOI 10.1007/s00240-013-0581-8

In the original article, one of the co-author's (Ahmad Shariftabrizi) family name has been published incorrectly. The correct family name should be Shariftabrizi.

The online version of the original article can be found under doi:10.1007/s00240-013-0581-8.

J. R. Eswara $(\bowtie) \cdot$ A. Shariftabrizi · D. Sacco

Department of Urology, Massachusetts General Hospital,

55 Fruit Street, Boston, MA 02114, USA

e-mail: jeswara@partners.org 